REFERENCES

Aird, I. (1949). Companion in Surgical Studies, p. 983. Livingstone, Edinburgh.

Bailey, H., and Love, R. J. M. (1941). A Short Practice of Surgery, 5th ed., D. 539. Lewis, London.

Boyd, W. (1947). Surgical Pathology, p. 4j4. Saunders, London.

Campbell, M. F. (1928). Surg. Gynec. Obstet., 47, 558.

Douglas, J. (1921). J. Amer. med. Ass., 76, 716.

Hammen, R. (1944). Studies on Impaired Fertility in Man, with Special Reference to the Male, pp. 22, 108. Oxford Univ. Press, London. Hotchkiss, R. S. (1945). Fertility in Men, p. 32. Heinemann, London.

Jeffcoate, T. N. A. (1946). British Medical Journal, 2, 185.

MacLeod, J., and Hotchkiss, R. S. (1946). Amer. J. Obstet. Gynec.; 52, 34.

Michelson, L., and Michelson, R. (1947). J. Amer. med. Ass., 134, 941.

Simmons, F. A. (1947). Proceedings of Conference on Diagnosis in Sterility, edited by E. T. Engle, p. 16. Charles C. Thomas, Blackwell, Oxford.

Skinner, H. L. (1941). Ann. Surg., 113, 123.

Turner, G. G. (1943). Operative Surgery, p. 2157. Cassell, London.

Tyler, E. T. (1951), J. Amer. med. Ass., 146, 307.

Wells. C. (1948). Textbook of Genito-urinary Surgery, edited by $H . P$ Winsbury-White, p. 588, Livingstone, Edinburgh.

\section{THE AURICULO-TEMPORAL. SYNDROME}

\section{BY}

PHILIP D. GOATCHER, M.B., F.R.C.S., F.R.C.S.Ed. Late First Senior Surgical Registrar, St. Paul's Hospital, London; Formerly Surgical Registrar, Whiston County Hospital, Liverpool

In 1897 Parkes Weber demonstrated the strange case of a youth who, following a suppurating lesion in the region of his left parotid gland, sweated on that side of his face when he ate food. Accompanying this there was a flushing on the same side of his face. Because the area involved corresponds to the cutaneous distribution of the auriculo-temporal nerve this condition became known as the auriculo-temporal syndrome. Lucie Frey described it again in 1923, and because of her work on the subject it is also known as Frey's syndrome.

The auriculo-temporal syndrome consists of redness and sweating over the temporal and p:e-auricular areas evoked by eating. It is a sequel of penetrating wounds, surgical incisions, or suppuration in the region of the parotid gland. The redness and sweating are not synchronous in appearance, the vasodilatation occurring first. Nor are they conterminous in distribution. There may be pain during eating, and sensory changes in the form of diminished or increased sensation in the same area are commonly present.

\section{Case Report}

A woman of 36 had the superficial part of her right parotid gland and adjacent fibrous tissue excised for chronic parotitis. From 2 years of age she had suffered from repeated attacks of painful inflammation, and periglandular fibrosis had produced a partial false ankylosis of the right temporo-mandibular joint. The operation prevented further attacks of parotitis and she was enabled to open her mouth enough to take food normally. Six months later it was noticed that during a meal sweat appeared on the side of her face and trickled down her cheek.

\section{Examination}

On examination a 4 -in. $(10-\mathrm{cm}$.) scar was seen running parallel to, behind, and below the right ramus, angle, and body of the mandible. Skin sensation was normal. The parotid gland was impalpable, and the orifice of Stensen's duct appeared normal, and saliva issued from it. When the patient was given a caramel to eat the skin on the affected side of the face became red. The hyperaemia extended over the forehead. temple, cheek, and ear. Within a minute, pinpoints of sweat appeared over a less extensive area (see Fig.). Within five minutes the sweat had accumulated into drops large enough to run down the cheek. When she stopped eating the sweating ceased, the hyperaemia faded, and the skin returned to normal.

\section{Anatomy and Aetiology}

It is necessary to consider the anatomy, so far as it is known, in order to appreciate the theories that have been produced to explain the mechanism. Secretory parasympathetic fibres from the glossopharyngeal nerve pass to the auriculo - temporal nerve, providing the parotid gland with secreto-motor fibres. The sweat glands of the face are innervated by the sympathetic outflow, the post-ganglionic fibres of which are believed by Wilson (1936) to be distributed with the peripheral branches of the trigeminal nerve. Sweating of the face in response to heat is mediated by sympathetic pathways, for destruction

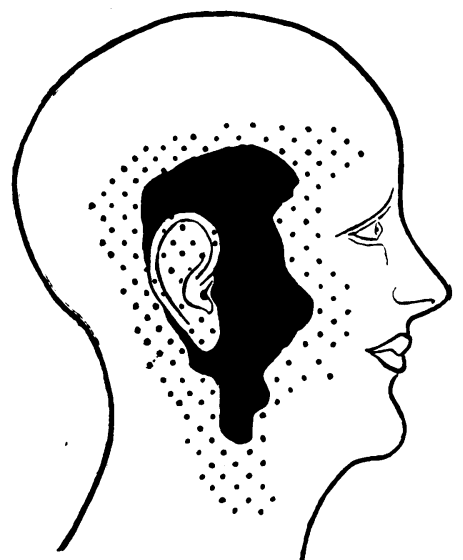

The black area represents the region of sweating. The stippled area represents the region of hyperaemia. of the cervical sympathetic chain reduces heat sweating (Guttmann, 1940). List and Peet (1938) suggest that there is parasympathetic innervation of sweat glands of the face. Wilson (1936) concluded that such fibres join the trigeminal nerve at some point distal to the sensory root. There is no evidence to suggest that they play any part in sweating under normal physiological conditions.

The auriculo-temporal syndrome occurs most often as as sequel of suppurative parotitis, which is so severe as either to rupture spontaneously or to require surgical incision and drainage (Parkes Weber, 1897; List and Peet, 1938 ; Freedberg et al., 1948; Pfeffer and Gellis, 1951). Trioumphoff (1926) reported 14 cases having an antecedent history of suppurative parotitis and mainly secondary to typhoid or typhus fevers. Frey's case followed a gunshot wound which caused a secondary parotitis. Cases have been reported following excision of parotid tumours, and it has been described following mumps and in cases of syringomyelia (Kaminsky, 1929; Wilson 1936).

\section{Mechanism}

The hyperaemia and sweating are a reflex response, the afferent component of which is stimulated by taste. It appears that the disorder lies in the efferent arc which involves nerve fibres in the region of the auriculo-temporal nerve.

It has been suggested that scar tissue involves and anchors autonomic fibres which are subjected to pressure when the parotid gland distends, as it does when food is tasted.

Those cases in which the syndrome occurs promptly after a salivary fistula closes support this theory. Needles (1936) reported a case of temporary parotid fistula complicating the excision of a parotid tumour. The appearance of the auriculo-temporal syndrome coincided with the closure of the fistula. Needles referred to a case of bilateral parotitis. One side had a fistula and the other none. The auriculotemporal syndrome occurred only on the side where there was no fistula. However, the phenomenon may occur when the parotid is either atrophied or functionless, and is not produced when pressure is exerted in the region of the scar.

Frey considered that the reflex was essentially a normal one, but that it had been accentuated through injury to the 
auriculo-temporal nerve with subsequent irritation of vasodilator fibres in the cicatrix of the sclerotic parotid gland. In that way she incriminated scar tissue.

Another hypothesis is that it is due to faulty regeneration of parotid secretory fibres (Thomas, 1927; Ford and Woodhall, 1938).

Since one cholinergic fibre can replace another (Dale, 1935), a fibre originally destined for salivary glands may communicate with a sympathetic fibre passing to the skin. In that way a stimulus which would normally produce salivation evokes sweating. The frequently associated evidence of nerve injury supports this view. This includes abnormalities of skin sensation, decreased sweating in response to heat, pain, and facial palsy which is either transient or permanent.

The time interval that occurs between the injury and the appearance of the syndrome also supports this hypothesis. Time must be allowed for Wallerian degeneration and subsequent regeneration to take place. This theory fails to explain those cases in which the latent period is only of a few days' duration. Furthermore, one would expect the sudomotor fibres of the auriculo-temporal nerve, coming from the cervical sympathetic, to produce vasoconstriction and pallor and not the reverse when they are stimulated.

Freedberg et al. (1948) offer the explanation that the auriculo-temporal syndrome represents a response of denervated and hypersensitive sweat glands to previously unapparent cranial sudomotor impulses.

Hypersensitivity of afferent structures following denervation is an accepted physiological finding in both cholinergic and adrenergic nerves. It is a logical expectation that hypersensitivity of the sweat glands of the face may follow division of sympathetic fibres in the auriculo-temporal nerve. Freedberg et al. (1948) and Langenskiöld (1946) demonstrated this sensitivity.

Haxton's (1948) observation that sympathetic block in the upper thorax stops the response suggests that acetylcholine comes from intact nerve endings.

From the above findings it becomes apparent that the mechanism of the auriculo-temporal syndrome is not fully explained.

\section{Allied Conditions}

There are other conditions which at least superficially resemble the auriculo-temporal syndrome. The slight symmetrical sweating that occurs on the faces of normal individuals when they eat spicy food is accepted as a normal reflex. Sometimes this reflex is exaggerated and the sweating excessive. Its relation to the auriculo-temporal gustatory sweating is hypothetical but suggestive. Pfeffer and Gellis (1951) refer to Mellenkoff's case of an infant with a transient phase of sweating from a small area in the region of one tibial tubercle when milk was taken.

The syndrome of "crocodile tears," which consists of lacrimation occurring as a reflex response to eating, resembles the auriculo-temporal syndrome. It follows facial palsy, usually with the site of lesion in the region of the geniculate ganglion. Another condition which resembles the auriculo-temporal syndrome was reported by Uprus et al. (1934). Their patient had previously had cervical glands excised. Gustatory sweating subsequently developed in the submandibular region on the same side as the operation.

\section{Prognosis and Treatment}

The hyperaemia and sweating may continue for the remainder of the patient's life, but a diminution of symptoms sometimes occurs (Payne, 1940).

Since the auriculo-temporal syndrome is benign and nonprogressive the patient can be reassured. If the discomfort warrants treatment the auriculo-temporal nerve may be divided surgically, but there are few records of this being done. Alcohol injection of the nerve is to be avoided because of possible injury to the facial nerve, and the value of radiotherapy is doubtful.

\section{Summary}

A case of the auriculo-temporal syndrome is reported. The anatomy is considered.

Aetiology is discussed.

Theories of explanation are reviewed.

Reference is made to allied conditions.

Prognosis and treatment are described.

I wish to thank Mr. J. A. Martinez for his permission to report this case.

REFERENCES

Dale, H. (1935). Proc. roy. Soc. Med., 28, 319. Freedberg, A. S., Shaw, R. S., and McManus, M. J. (1948). J. clin. Invest. 27. 669 .

Frey, (1923), Rev. neurol., Paris, 2, 97.

Frey, L. (1923). Rev. neurol., Paris, 2, 97.

Guttmann, L. (1940). J Anat, Lond.

Kaminsky. S. D. (1929). Dtsch. Z. Nervenheilk., 109, 296.

(1946). Acta chir. Scand., 93, 294.

List, C. F. and Peet, M. M. (1938). Arch. Neurol. Psychiat., Chicago, 40, 269,443 .

Needles, W. (1936). Ibid., 35, 357.

Payne, R T (1940), Lancet, 1,634

Pfeffer, W Paediatrics, 7, 670.

Thomas, A. (1927). Rev. neurol., Paris, 1, 447.

Trioump. (1926). Presse méd 34, 1350.

Uprus, V. Gaylor, J. B., and Carmichael, E. A. (1934). Brain, 57, 443.

Wrus, ., Gaylor, (1897), Clin. Soc. Trans., 31, 277

Wilson, W. C. (1936). Clin. Sci., 2, 273.

\section{RADIO-IODINE MEASUREMENTS OF THYROID FUNCTION DURING AND AFTER P.A.S. TREATMENT OF TUBERCULOSIS}

BY

J. A. BALINT, M.B., M.R.C.P.

Medical Registrar, Central Middlesex Hospital

RUSSELL FRASER, M.D., F.R.C.P.

Reader in Medicine, Postgraduate Medical School of London

AND

M. G. W. HANNO, M.D., M.R.C.P.Ed.

Lecturer in Medicine and Therapeutics, Alexandria University, Egypt

(From the Department of Medicine, Postgraduate Medical School of London)

Over the past three years there have been reported nine cases of hypothyroidism with goitre occurring during para-amino salicylic acid (P.A.S.) treatment (Bergqvist and Maré, 1951, 1952; Clausen and Kjerulf-Jensen, 1951 ; Komrower, 1951; Librach, 1952; Davies and Galbraith, 1953). As many thousands of patients have received this treatment this seems a small incidence which may have depended on some special susceptibility in these few patients. Others have reported simple enlargement of the thyroid gland without signs of disordered thyroid function during P.A.S. treatment-that is, lesser antithyroid effects (Bergqvist and Maré, 1951, 1952; Hamilton, 1953); indeed, in some of the cases reported as goitre with myxoedema the evidence of thyroid deficiency has been slight. Because of these reports we have endeavoured to assess whether doses of P.A.S. commonly used clinically entail much risk to thyroid function. Radio-iodine tests of thyroid uptake have therefore been carried out on an un- 